\title{
Geometric morphometrics in herpetology: modern tools for enhancing the study of morphological variation in amphibians and reptiles
}

\author{
Antigoni Kaliontzopoulou ${ }^{1,2}$ \\ ${ }^{1}$ CIBIO/UP, Centro de Investigação em Biodiversidade e Recursos Genéticos, Campus Agrario de Vairão, 4485-661 Vairão, Portugal. \\ ${ }^{2}$ Department of Ecology, Evolution, and Organismal Biology, Iowa State University, Ames, Iowa 50011, USA. \\ * Correspondence: CIBIO/UP, Centro de Investigação em Biodiversidade e Recursos Genéticos, Campus Agrario de Vairão, $4485-661$ \\ Vairão, Portugal. Phone: +351 252660411, Fax: +351 252661780, E-mail: antigoni@mail.icav.up.pt
}

Received: 30 August 2011; received in revised form: 8 October 2011; accepted: 10 October 2011.

The use of geometric morphometrics for studying phenotypic variation in amphibians and reptiles has visibly increased in the last decade. These modern tools provide a robust statistical framework to study organismal shape while preserving the geometric properties of the studied structures and thus improve our capacity for investigating patterns of morphological variation, and understanding their ecological and historical causes. Their application in herpetology has shed new light to the remarkable diversity observed among extant and extinct amphibians and reptiles. Here I first briefly consider the historical emergence of geometric morphometric methods, trying to provide a practical guide for herpetologists interested in implementing these tools to their investigation. I then review the wide array of published studies using geometric morphometrics to investigate morphological patterns in amphibians and reptiles. Across different investigation fields, an emergent pattern is the existence of general similarities, but also profound differences, among members of higher taxonomic groups. Size-shape allometry is a common pattern in many groups, but remarkable variation of allometric trajectories exists among closely related taxa. Sexual dimorphism has been extensively studied in reptiles, but less so in amphibians, while the contrary is true for phenotypic plasticity. The use of geometric morphometrics has allowed the detection of potentially adaptive shape patterns and the investigation of their causes. Finally, these methods have been invaluable in the study of fossils and have provided a better understanding of the paleobiology of extinct taxa.

Key words: adaptation; allometry; geometric morphometrics; paleontology; phenotypic plasticity; sexual dimorphism.

Morfometría geométrica en herpetología: nuevas herramientas para promover el estudio de la variación morfológica en anfibios y reptiles. El uso de la morfometría geométrica para estudiar la variación fenotípica en anfibios y reptiles ha aumentado notablemente durante la última década. Esta nueva herramienta proporciona un marco estadístico sólido para estudiar la forma de los organismos preservando las propiedades geométricas de las estructuras analizadas, mejorando así la comprensión de los factores ecológicos e históricos que explican los patrones de variación morfológica. Su aplicación en herpetología proporciona una nueva forma de explorar la diversidad morfológica de anfibios y reptiles tanto actuales como extintos. En esta revisión comienzo examinando la secuencia histórica que llevó a la aparición de la morfometría geométrica, tratando de ofrecer también una guía práctica para aquellos herpetólogos interesados en incorporar esta herramienta en su investigación. Después reviso un amplio muestrario de trabajos en los que la morfometría geométrica se usa para estudiar patrones morfológicos en anfibios y reptiles. Una pauta que emerge repetidamente es la existencia de similitudes generales, pero también de profundas diferencias, entre los miembros de los grupos taxonómicos de mayor rango. La existencia de una relación alométrica entre tamaño y forma es común en muchos grupos, pero también se observa una variabilidad considerable en las trayectorias alométricas entre taxones hermanados. El dimorfismo sexual se ha estudiado extensivamente en reptiles, pero no tanto en anfibios, mientras que con la plasticidad fenotípica ocurre lo contrario. El uso de la morfometría geométrica permite la detección de variaciones adaptativas en los patrones morfológicos y la investigación de sus causas. Finalmente, estos métodos tienen un valor incalculable para el estudio de organismos fósiles y proporcionan una mejor compresión de su paleobiología.

Key words: adaptación; alometría; dimorfismo sexual; morfometría geométrica; paleontología; plasticidad fenotípica. 
Morphology is undoubtedly one of the main components of an organism's phenotype. As such, morphological traits have always been at the centre of attention of biological research, comprising important pieces of evidence for a wide variety of investigation fields. From traditional taxonomy and the modern school of systematics, through physiology, development, ecology, biogeography, and all the way to modern evolutionary biology, practically all biological fields include questions and hypotheses related to how morphological variation emerges and how it is distributed across temporal and spatial scales. Geometric morphometrics (GM) revolutionised the way we measure, study and perceive morphological diversity (Rohlf \& MARCUs, 1993; AdAMs et al., 2004). By establishing a solid mathematical basis for the study of organismal shape, while preserving the geometric properties of the structures of interest, GM methods provide a powerful tool for depicting and studying morphological variation in a more realistic and integrated manner than previous morphometric tools (BOOKSTEIN, 1996; ROHLF, 2000a). Amphibians and reptiles, being excellent model organisms, have been the subject of extensive morphological research, often serving as paradigmatic cases in the study of phenotypic variation. Accordingly, over the past two decades, herpetologists have taken advantage of the modern toolkit of GM to further enhance our understanding of the astonishing morphological variety that exists across amphibian and reptile taxa. Since the early development of GM tools, most extant - and several extinct herpetofaunal groups have been investigated using these methods.
This review aims at putting together an up-to-date account of how GM methods have been implemented in herpetology until today, also providing a comprehensive basis for herpetologists interested in exploring these methods in their research. Although I have tried to include all studies to which I had access and provide examples from all herpetofaunal groups, this is not meant to be an exhaustive account from a taxonomical perspective, but rather to give insight on how GM methods have advanced our understanding of the patterns and processes underlying the phenotypic diversification of our study organisms.

GEOMETRIC MORPHOMETRICS: WHY AND HOW?

\section{The birth of GM or how GM is different}

Morphometrics, the quantitative study of biological shape variation and its covariation with other variables (BOOKSTEIN, 1991; DRYDEN \& MARDIA, 1998), may be seen as the successful outcome of the long-standing interest in organismal form. Ever since Aristotle biologists have been intrigued by the huge diversity of forms we encounter in nature and the causes and processes that create it. However, such interest was only put on a quantitative basis with the statistical advances made during the $19^{\text {th }}$ and $20^{\text {th }}$ centuries, which led to the emergence of biometry as a formal discipline (SOKAL \& ROHLF, 1995; Slice, 2005; MitTeroecker \& GunZ, 2009). The development of statistical tools for analysing multivariate data opened a new door to the description and study of complex phenotypes. This was achieved through the quantification of a number of linear distances, 
counts, ratios or angles, describing the properties of a morphological trait of interest (ADAMS et al., 2004; SLICE, 2005). The application of multivariate statistics on the above biometric variables then allowed for the testing of specific biological hypotheses about an organism's multivariate phenotype (i.e. "traditional morphometrics"; MARCUS, 1990). However, morphometrics still suffered some shortcomings which troubled morphometricians and urged for solutions. These problems deserve our attention, since their resolution was the basic motivation for the development of the field of GM and they provide direct insight into how this new methodology differs from traditional morphometrics.

The birth of GM is tightly linked to four considerations related to biological form: size, homology, shape description and visualisation. With size and its effect on other morphological traits being of central importance to the evolution of all living organisms (Gould, 1966), it was soon evident that in order to study biological form, a full mathematical definition of size was in order, due both to practical and to theoretical reasons (Bookstein, 1989a; SliCe, 2005). Numerous solutions were proposed (see ROHLF \& BOOKSTEIN, 1987 for review and comparison), but no solid argument could definitely support the use of a single method. A similar problem existed as to the homology of the studied traits, in the sense of the operational, reproducible definition of the quantities to be measured and compared (BOOKSTEIN, 1982; SLICE, 2005). Yet an additional concern regarded the selection of variables used for shape description; since the geometric relationships between linear measurements were not included in the dataset, one could neither predict nor guarantee the statistical differentiation of shapes known to be different (BOOKSTEIN, 1982, 1996; SLICE, 2005). Finally, since the geometry of the studied objects was not captured, morphometric data could not be effectively used to directly visualise shape variation related to other biological variables of interest (ADAMS et al., 2004). All the above adversities led to the development of GM methods.

\section{What is GM and how to use it}

The "revolution in morphometrics" (RoHLF \& MARCUS, 1993) started by advances in the application of outline and landmark tools for the geometrical study of organismal shape (BOOKSTEIN, 1986; ROHLF, 1986) and the simultaneous development of statistical theory for shape analysis (KENDALL, 1984, 1985). The combination of landmark techniques for capturing organismal form with a newly introduced, statistically robust shape theory led to the growth of a set of morphometric methods that preserved the geometric properties of the studied objects, namely GM (Slice, 2005; MitTeroecker \& GunZ, 2009). The raw data used for GM consist of outline data describing the bounding edge of the structure of interest or, more frequently, of Cartesian coordinates of landmark locations (Slice, 2005; MitTeroecKer \& GunZ, 2009). Outline data were the first to be used, but they were later largely abandoned, especially after the introduction of semi-landmark methods that incorporate boundary curve information directly into landmark-based analyses (BOOKSTEIN, 1997; MitTEROECKER \& GuNZ, 2009). Since two- and threedimensional landmark-based GM methods are more frequently used today, I will concen- 
trate on these methods for a practical review. However, the interested reader can explore the published bibliography on outline methods (see among others ROHLF \& ARCHIE, 1984; FERSON et al., 1985; ROHLF, 1986, 1990; ADAMs et al., 2004).

Landmark-based GM analysis begins with the definition of landmarks (Table 1, Fig. 1a). Simplistic as this may seem, it is a central part of biological inference: "Landmarks are the points at which one's explanations of biological processes are grounded" (BOOKSTEIN, 1991). It is through the definition of landmarks, based on biological intuition and previous observation of the organisms of interest, that the biologist will manage to fully capture the shape of interest. Once landmarks have been defined, these are digitised in a number

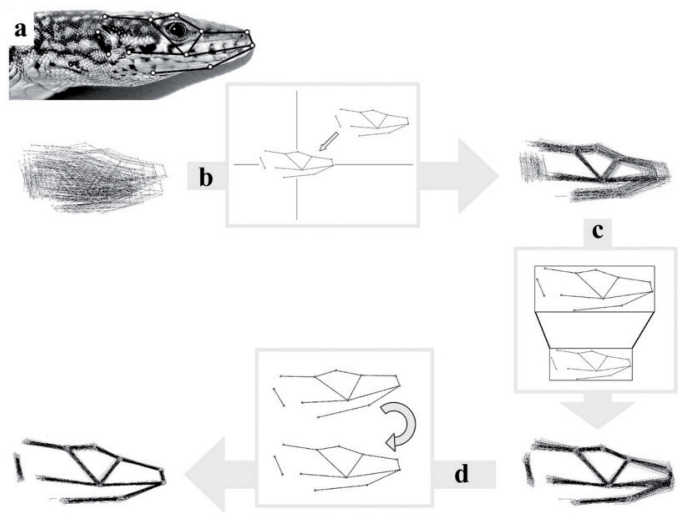

Figure 1: Removing non-shape variation from landmark coordinates through Generalized Procrustes Analysis (GPA: ROHLF \& SLICE, 1990). Once landmarks have been defined (a) and digitised in a number of specimens, their coordinates are first translated (b) by placing their centroid to the origin of a Cartesian system. Then they are scaled (c) to unit centroid size. Finally, they are rotated (d) using a least-squares criterion. This way landmark coordinates are superimposed to a common coordinate system and non-shape variation is removed. of specimens, resulting in a collection of Cartesian coordinates. These coordinates still include non-shape information (size, orientation and position) and need to be mathematically processed in order to obtain shape variables. The dominant procedure today uses shape variables lying in Kendall's shape space (or most frequently an approximation in a space tangent to the mean shape of the studied sample), Procrustes distance being the associated metric (Table 1). While several methods were proposed in the past for obtaining shape variables from landmark coordinates, methods using Kendall's space have been proven to be the most powerful and statistically robust (RoHLF, 1999, 2000a,b, 2003). In order to obtain shape variables, landmark configurations are first superimposed using a least-squares procedure, namely Generalized Procrustes Analysis (GPA, Table 1, RoHlF \& SLICE, 1990). GPA removes variation due to digitizing location, scale and orientation through the optimal translation (Fig. 1b), scaling (Fig. 1c) and rotation (Fig. 1d) of landmark coordinates. The specimen points aligned through this procedure can then be projected into a linear shape space tangent to Kendall's shape space (Table 1; ROHLF, 1999; Slice, 2001, 2005; MitTeroecKer \& GunZ, 2009), where the Euclidean distances between observations closely approximate Procrustes distances in Kendall's space. One should be aware that, in addition to GPA, several other superimposition techniques exist, with potential benefits in particular datasets (SIEGEL \& BENSON, 1982; BOOKSTEIN, 1991; ZELDITCH et al., 2004; SLICE, 2005).

Once non-shape variation has been removed, the superimposed landmark coordinates of specimens not differing in shape will per- 
Table 1: Glossary of terms frequently used in geometric morphometrics*.

\begin{tabular}{|c|c|}
\hline Term & Description \\
\hline Allometry & Shape change associated to size change. \\
\hline Centroid size & $\begin{array}{l}\text { The size measure used in GM. It is calculated as the square root of the sum of squared dis- } \\
\text { tances of each landmark from the centroid of the landmark configuration. }\end{array}$ \\
\hline Consensus configuration & $\begin{array}{l}\text { A landmark configuration intended to represent the central tendency (for example mean } \\
\text { shape) of an observed sample. Often a consensus configuration is computed to optimize } \\
\text { some measure of fit to the full sample: in particular, the Procrustes mean shape is computed } \\
\text { to minimize the sum of squared Procrustes distances from the consensus landmarks to those } \\
\text { of the sample. }\end{array}$ \\
\hline Deformation grid & $\begin{array}{l}\text { The visual representation of a shape transformation as modelled using the thin-plate spline, } \\
\text { based on D'Arcy Thompson's idea of using grids to represent a shape difference. }\end{array}$ \\
\hline $\begin{array}{l}\text { Generalized Procrustes } \\
\text { Analysis (GPA) }\end{array}$ & $\begin{array}{l}\text { A generalized superimposition method that works by minimising the partial Procrustes dis- } \\
\text { tance over all sampled shapes by a least-squares fitting procedure. }\end{array}$ \\
\hline Kendall's shape space & $\begin{array}{l}\text { The geometric setting for analyses of Procrustes distances among arbitrary sets of landmarks. } \\
\text { Each point in this shape space represents the shape of a configuration of points in some } \\
\text { Euclidean space, irrespective of size, position, and orientation. }\end{array}$ \\
\hline Landmark & $\begin{array}{l}\text { A specific point on a biological form or image of a form located according to some } \\
\text { rule. BOOKSTEIN (1991) recognised three categories of landmarks, depending on the } \\
\text { criteria used for their definition: Type I landmarks correspond to points clearly defined } \\
\text { by some local property, such as the juxtaposition of different tissues; Type II landmarks } \\
\text { are defined purely based on geometric, not biological, properties, such as the maxi- } \\
\text { mum curvature of a structure; finally, Type III landmarks are the less robustly defined } \\
\text { ones, since they are located in relation to other points in the structure. Type III land- } \\
\text { marks can be incorporated in GM analyses, but are not in fact considered true land- } \\
\text { marks and caution should be taken when using them. }\end{array}$ \\
\hline Partial warps & $\begin{array}{l}\text { An auxiliary structure for the interpretation of shape changes and shape variation in sets of } \\
\text { landmarks. They are eigenvectors of the bending energy matrix that describes the net local } \\
\text { information in a deformation along each coordinate axis. }\end{array}$ \\
\hline Principal warps & $\begin{array}{l}\text { Eigenfunctions of the bending-energy matrix interpreted as actual warped surfaces (thin- } \\
\text { plate splines) over the picture of the original landmark configuration. }\end{array}$ \\
\hline Procrustes distance & $\begin{array}{l}\text { Approximately, the square root of the sum of squared differences between the positions of the } \\
\text { landmarks in two optimally (by least-squares) superimposed configurations at centroid size. } \\
\text { This is the metric for Kendall's shape space, and thus the distance measure used in GM. }\end{array}$ \\
\hline Procrustes residuals & $\begin{array}{l}\text { The set of vectors connecting the landmarks of a specimen to corresponding landmarks in } \\
\text { the consensus configuration after a Procrustes fit. The sum of squared lengths of these vec- } \\
\text { tors is approximately the squared Procrustes distance between the specimen and the consen- } \\
\text { sus in Kendall's shape space. The partial warp scores are an orthogonal rotation of the full } \\
\text { set of these residuals. }\end{array}$ \\
\hline Relative warps & $\begin{array}{l}\text { Principal components of partial warp scores. In a relative warps analysis, the parameter } \alpha \text { can } \\
\text { be used to weight shape variation by the geometric scale of shape differences. }\end{array}$ \\
\hline Shape & $\begin{array}{l}\text { The geometric properties of a configuration of points that are invariant to changes in trans- } \\
\text { lation, rotation, and scale. }\end{array}$ \\
\hline Thin-plate spline & $\begin{array}{l}\text { An interpolation function used to model the difference in shape between two objects by } \\
\text { minimising the bending energy of the deformation. It provides a unique solution to the } \\
\text { construction of D'Arcy Thompson-type deformation grids for data in the form of two land- } \\
\text { mark configurations. }\end{array}$ \\
\hline
\end{tabular}

* Compiled and augmented from SLICE et al. (1996) and ZeLDiTCH et al. (2004). 
fectly coincide. In turn, specimens of different shape will present at least some differences in landmark positions. The largest the shape difference between specimens, the largest the difference in the positions of homologous landmarks after superimposition. Such shape difference is quantified through the Procrustes distance metric, which allows for statistical comparisons and hypothesis testing (SLICE, 2005; MitTeroecker \& GunZ, 2009). In this sense, then, Procrustes residuals (i.e. landmark coordinates after superimposition) can be used as shape variables to investigate shape variation. However, Procrustes residuals suffer the statistical adversities of not being a fullrank set of variables (due to superimposition) and of being non-Euclidean in nature, which frequently complicates their statistical treatment since they cannot be subjected to analysis using linear models. While this adversity can be overcome through projection into a tangent, Euclidean space, the usual approach is to perform a series of mathematical operations to model shape variation. This is done using the thin-plate spline. The thin-plate spline is an interpolation technique borrowed for use in morphometrics from the fields of computational surface theory and computer graphics (BOOKSTEIN, 1989b, 1991). Imagine that the shape of interest, represented by a configuration of landmarks, lies on an infinitely thin, flat, metal plate of infinite size. The change into another shape can be obtained through a set of vertical displacements of the metal plate in a direction perpendicular to its surface, one Cartesian coordinate at a time. By minimising the energy necessary to bend the metal plate between two shapes (bending energy) we obtain a criterion for parsimoniously describing and modelling shape chan- ge. The descriptors resulting from the application of the thin-plate spline are partial warps (Table 1), which are in fact the eigenvectors of the bending-energy matrix and are orthogonal components describing shape variation according to spatial scale. The partial warp scores (together with the uniform components of shape variation) of each individual can then be used as shape variables for multivariate statistical analyses (SLICE, 2005).

In addition to providing Euclidean shape variables for statistical hypothesis testing, the thin-plate spline is an essential tool for visualising shape variation in an integrated and intuitive manner (SLICE, 2005). Since the thinplate spline is in fact an interpolation function, it can be used to map the deformation in shape between two objects (BOOKSTEIN, 1991). This is done through a mathematically formal realization of D'Arcy Thompson's idea of transformation grids (THOMPSON, 1917), a solution long sought by morphometricians (BooksteIn, 1996). These maps of shape change, referred to as deformation grids (Table 1), use a visual representation of a wire mesh to depict the bending necessary to transform one shape into another, a procedure known as warping (Fig. 2). This is one of the most important advances provided by GM methods: since the geometry of the studied objects is preserved throughout the analysis, shape differences between objects can be directly described in terms of differences in the deformation grids representing these objects (AdAms et al., 2004; Slice, 2005; MitTEROECKER \& GUNZ, 2009). Several software packages are available for conducting all the above GM analyses, performing statistical comparisons and visualising the results (see Appendix 1). 


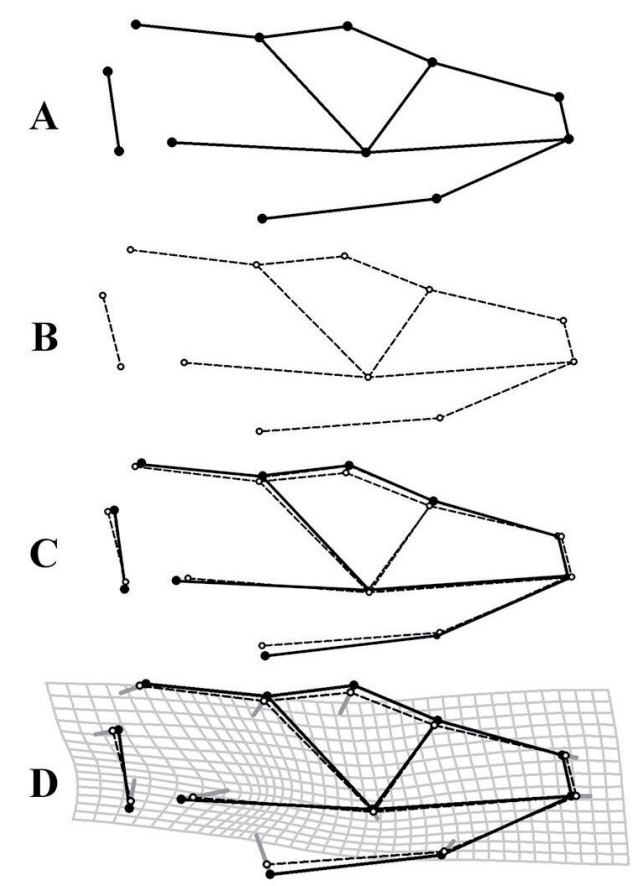

Figure 2: How the thin-plate spline can be used to visualize shape differences found from landmarkbased GM methods. In this example, shapes $\mathrm{A}$ and $\mathrm{B}$ are being compared. Once landmark configurations have been aligned through superimposition $(\mathrm{C})$, shape differences between them can be visualised as the deformation caused on a wire mesh which is bended from one shape to the other (D). Linear vectors on the landmarks represent the direction of change for each of them from shape A into shape B (exaggerated five-fold to enhance visualisation).

\section{GM IN HERPETOLOGY:}

\section{A TAXONOMICAL ACCOUNT}

Herpetologists have been increasingly using GM techniques to study morphological variation in amphibians and reptiles over the last decade. Focusing on the studies considered here, a visible increase in the use of GM methods for studying extant or extinct amphibians and reptiles is observed after the year 2000, from less than five publications per year between 2000 and 2003 to an average of about 13 publications per year after 2007 (Fig. 3). Among amphibians, both anurans and urodeles have been investigated, but GM methods have not yet been applied - to the best of my knowledge - for studying caecilians. Among reptiles, saurians are the most studied group, with a total of 25 publications, followed by chelonians (19 studies). Other groups are visibly less explored, with only three studies in snakes and three in crocodiles, while, as far as I am aware, amphisbaenians are still to be studied. GM tools are also extensively used for studying extinct amphibian and reptile taxa, with an important contribution to the total number of studies (Fig. 3) and remarkable results (see below).

\section{STUDYING PHENOTYPIC VARIATION: FIELDS OF APPLICATION}

The integrated study of shape through GM motivated an explosion of morphological investigation in amphibians and reptiles and expanded our knowledge of patterns of variation and their causes. In the following section, I provide a question-based review of published studies, aiming at describing general shape patterns observed across herpetofaunal taxa and discussing their potential causes as seen by herpetologists.

\section{Allometric patterns: shape change due to size}

GM tools have been a cornerstone contribution to the study of development and ontogenetic shape change. By enhancing shape quantification and shape change visualisation, GM methods have provided the possibility not only 


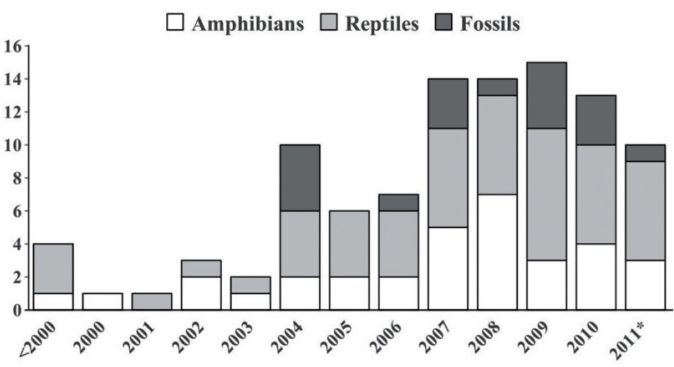

Figure 3: Yearly evolution of the number of publications using GM methods to analyse morphological variation in extant and extinct amphibians and reptiles. Data retrieved from Google Scholar and Isi Web of Science. * Records concerning 2011 include studies published or in press until July 31 .

of accurately describing complex shapes, but also of understanding exactly how shape changes throughout an organism's development (LAWING \& POLLY, 2010). Most studies investigating allometric relationships, both in an ontogenetic and static context of allometry (i.e. Gould, 1966), indicate that large part of the shape variation observed is attributable to sizeshape allometry (see MONTEIRO \& ABE, 1997; Birch, 1999; Bonnan, 2007; SMITH \& COllyer, 2008; Piras et al., 2010; CHIARI \& Claude, 2011; IvanOvić et al., 2011 for illustrative examples from different groups). Caution is advised to avoid conceptual misunderstandings: while GM methods remove size variation through GPA or similar superimposition procedures, the allometric dependence of shape on size still remains in the data and can be investigated (MONTEIRO, 1999). Statistically, since shape variables produced through GM techniques are size-free, any significant association with size (either represented by centroid size or any other size variable) indicates deviation from isometry (ZELDITCH et al., 2004).

Extensive research about ontogenetic shape change at different developmental stages has been carried out mainly in amphibians, revealing both similarities and profound differences among groups. Pre-metamorphic shape ontogeny of the chondrocranium in anurans seems to generally follow a common pattern, at least in species of the genera Bufo, Pelodytes, Rana and Telmatobius (LARSON 2002, 2004, 2005; CANDioti, 2008; GARriga \& Llorente, in press). In these anuran species, general patterns of skull development include the reduction of the sensory capsules and a hypermetric or isometric growth of trophic structures (LARSON, 2002, 2004), in line with predictions made for all tetrapods (EMERSON \& BRAMBLE, 1993). Interestingly, these studies also attest that the development of the chondrocranium does not seem to be tightly linked to that of the hind limb, thus rendering Gosner stages - a developmental staging system frequently used in anurans (GOSNER, 1960) - a relatively poor indicator of chondrocranial differentiation (LARSON, 2002). Similarly, species of newts studied show generally congruent patterns, the skull base and rostral portion being the areas more profoundly modified throughout ontogeny (IVANOVIĆ et al., 2007, 2008). However, while general trends appear relatively uniform, allometric trajectories frequently vary among closely related species (LARSON, 2005; IVANOVIĆ et al., 2007, 2008), providing a potentially important mechanism of morphological differentiation, both in extant and extinct taxa (WITZMANN et al., 2009). The same is true for body shape variation before and through metamorphosis in newts (VAN BUSKIRK, 2009; IVANOVIĆ et al., 2011), although further studies should investigate the generality of the results obtained for Triturus, since remarkable variation of allometric patterns has been observed in some cases (VAN 
BUSKIRK, 2009). Finally, caution should be taken when extrapolating between groups or even populations of the same species, since allometric trajectories of amphibian shape have been found to present radical modifications in both plastic and adaptive responses to environmental variation (see below).

Allometric shape variation has been also extensively investigated in reptiles, again revealing concordance of general trends, but also significant variation between closely related species. In lizards, the general pattern of skull allometry, both in an ontogenetic (MONTEIRO \& ABE, 1997; Kaliontzopoulou et al., 2008; RAIA et al., 2010) and static (BRUNER \& Costantini, 2007; CosTANTINI et al., 2010; LJUBISAVLJEVIĆ et al., 2011; ZUFFI et al., 2011) context, includes a relative shortening of the anterior area and an enlargement of the posterior region. Interestingly, some studies have reported a lack of an allometric relationship between head shape and size in some lizard species (VIDAL et al., 2005, 2006); however, these results should be considered with caution, since in the above studies, allometry was investigated by bivariate regression of the first principal component of shape variation on centroid size, thus potentially providing an incomplete view of allometric patterns. In fact, multivariate regression of all shape variables (i.e. partial warps) on centroid size or other size measures are better suited for investigating size-shape relationships in a GM context (KlingenberG, 1996; Monteiro, 1999), since size may significantly contribute to the observed shape patterns even without being the main source of variation (captured by principal components analysis). As for amphibians, allometric trajectories of the skull have been found to vary extensively among species
(LJUBISAVLJEVIĆ et al., 2010), but intraspecific variation seems to be less common.

Regarding other reptile groups, size variation also seems to be a main determinant of shape variation in turtles, including ontogenetic, static and evolutionary allometric effects (Claude et al., 2003, 2004; DePECKER et al., 2006; ANGIELCZYK, 2007; MYERs et al., 2007; NisHIZAWA et al., 2010; ANGIELCZYK et al., 2011; Chiari \& Claude, 2011). Different characters show varying degrees of variation in allometric trajectories. For example, evolutionary allometry of skull shape seems to be constrained, and similar to intraspecific allometry (Claude et al., 2004), while extensive variation is observed between ecologically distinct groups in the shoulder girdle (DEPECKER et al., 2006). The trait most frequently studied in turtles, the shell, also shows varying degrees of allometric modifications. For instance, CHIARI \& Claude (2011) described substantial modification of growth trajectories between two closely related lineages of Galápagos tortoises, while the same seems to be the case for the miniaturised species of emydine turtles (ANGIELCZYK, 2007). Other reptile groups have been less investigated; however, extensive variation seems to exist in skull ontogenetic patterns of crocodiles (MONTEIRO et al., 1997; PIRAS et al., 2010), while size variation seems to be a moderate source of skull shape variation as compared to other factors in the rhynchocephalians (JONES, 2008).

\section{Sexual dimorphism}

Sexual dimorphism (SD) is a ubiquitous feature of many animal taxa and the application of GM has importantly enhanced our understanding of the proximate and evolutio- 
nary causes of shape SD. Surprisingly, studies using GM methods to address SD in amphibians are very limited. Some studies investigated the effect of sex on shape and reported significant SD (IVANOVIĆ et al., 2007, 2008, 2009), but in these cases sex was treated as a side variable, rather than being the main focus of interest. This markedly contrasts with the extensive investigation of shape SD using GM in reptiles, and particularly in lizards. As is true for allometric patterns (see above), the analysis of lizard SD using GM has focused mainly on head and skull shape and has revealed a general resemblance of global patterns, but also significant variation across groups, although the number of studies is visibly skewed towards the lacertids. Indeed, head/skull shape is sexually dimorphic in all lacertid lizards that have been examined (i.e. Algyroides: LJUBISAVLJEVIĆ et al., 2011; Dalmatolacerta and Dinarolacerta: LJUBISAVLJEVIĆ et al., 2010; Lacerta: BRUNER et al., 2005; COSTANTINI et al. 2007; Podarcis: Kaliontzopoulou et al., 2007, 2008; LJUBISAVLJEVIĆ et al., 2010; RAIA et al., 2010). In all of the aforementioned genera, sexual shape variation is mainly located at the posterior region of the head, males always presenting a more enlarged parietal (dorsally) and tympanic (laterally) areas as compared to females (Fig. 4). The same trend is also observed in other phylogenetically disparate lizard groups, such as iguanids of the genus Liolaemus (VIDAL et al., 2005) and Tarentola geckos (ZuFFi et al., 2011). Additionally, in all the above examples, investigation of the proximate causes of shape SD indicated that males and females follow common allometric slopes when considering the relationship between head shape and size (as represented by centroid size). Interestingly, however, when size variation is taken into account, some studies indicate size-independent differentiation of head shape between the sexes (i.e. difference of allometric regression intercepts, KaliOnTZOPOUlOU et al., 2008), while others indicate size SD as the only source of shape SD (BRUNER et al., 2005; LJUBiSAVLJEVIĆ et al., 2010). This, together with the variation of allometric slopes observed among closely related species (Ljubisavljević et al., 2010) and the complete lack of head shape dimorphism observed in some instances (MONTEIRO \& Abe, 1997), indicates that important variation may exist across species, urging for further investigation.

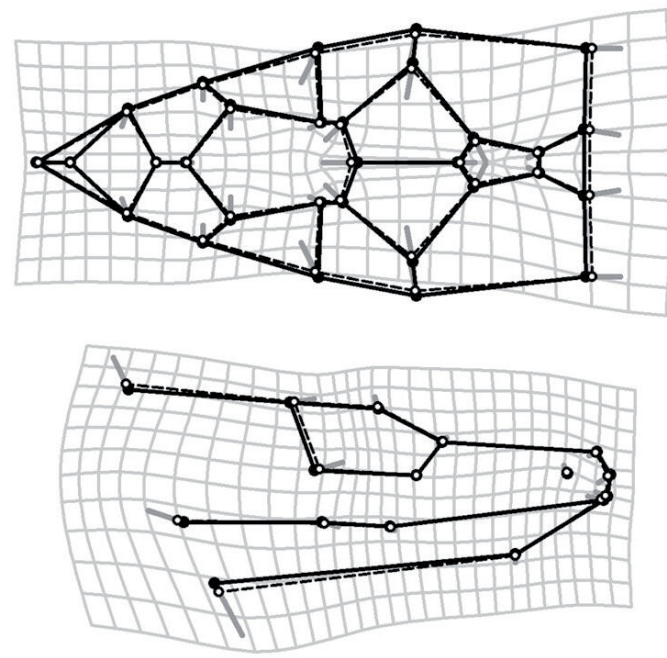

Figure 4: Typical pattern of head shape sexual dimorphism in lacertid lizards, characterised by a relative enlargement of the posterior region and reduction of the anterior area in males. In this case, the transformation of female (filled symbols, continuous line) to male (open symbols, dashed line) shape in Podarcis bocagei is represented through deformation grids for the dorsal (top) and lateral (bottom) view of the head (modified from KALIONTZOPOULOU et al., 2008). Shape differences are exaggerated five-fold to enhance visualisation. 
A promising line of research may be the elucidation of the functional significance of head shape SD as captured by GM methods, in order to provide further evidence to the long-standing hypothesis of sexual selection acting on bite force as the main determinant of the observed morphological patterns (HERREL et al., 2007; HuYghe et al., 2009; KALIONTZOPOULOU et al., in press).

The investigation of SD using GM is relatively limited in turtles and snakes, but some general conclusions may be drawn. In turtles, some studies have reported significant SD in shell shape, which is the only trait that has been examined. However, there is a marked discordance among authors regarding the comparison between traditional and geometric morphometrics for quantifying shape in turtles; while some authors use GM as a powerful method for capturing patterns invisible to traditional approaches, such as SD in hatchlings (VAlenzuela et al., 2004; Lubiana \& FERREIRA JÚNIOR, 2009), others report a weaker $S D$ in geometric shape as compared to that observed using linear measurements (CHIARI \& Claude, 2011). Such a disagreement may be due to differences in the degree and direction of shape SD in different taxa, a possibility supported by the limited data available (Valenzuela et al., 2004; Ceballos \& VAlenZuela, 2011). A different pattern is observed in snakes, although the reduced number of studies once again hinders the extraction of definite conclusions. The available studies indicate that head/skull shape SD in snakes is non-existent or of relatively low importance, at least as compared to other sources of variation, such as geographic locality (MANIER, 2004; SMITH \& COLLYER, 2008) or phylogenetic signal (GeNTILLI et al., 2009). Clearly, patterns of shape SD and its variation in turtles and snakes needs to be further investigated in the future.

\section{Shape evolution: adaptation and phenotypic plasticity}

The search for causal factors that may explain the extensive morphological variation we observe in many animal groups has always been a fascinating field of investigation. GM methods have enhanced our capacity of describing shape variation and associating it with both ecological factors and performance measures, thus providing evidence of the adaptive potential of certain shape traits. Extensive herpetological research has focused on the search for such variation, shedding new light on the way amphibians and reptiles respond morphologically to environmental disparity.

GM-based studies of the evolution of turtle shell shape provide an exemplar system to the study of adaptation. The shell represents a fundamental component of the turtle phenotype and it is recognised as one of the most remarkable novelties among tetrapods (BURKE, 1989). Moreover, the shape of the shell has been shown to present an important heritable component, thus holding strong evolutionary potential (MYERS et al., 2006). At the same time, turtles have diversified to occupy a wide range of ecological niches, while preserving a basic body plan, thus constituting exceptional model organisms for studying the consequences of ecological diversification on morphological traits. Several components of habitat use have been shown to directly influence turtle body shape. The differentiation between aquatic and terrestrial life is undoubtedly one of the main causes of turtle phenotypic diversification, being reflected in the shape of the carapace (CLAUDE 
et al., 2003; Rivera \& Claude, 2008; STAYTON, 2011), the plastron (CLAUDE et al., 2003; ANGIELCZYK et al., 2011), the skull (CLAUdE et al., 2004) and the shoulder articulation (DEPECKER et al., 2006). Diet is an additional niche dimension involved in skull differentiation in turtles (CLAUDE et al., 2004), while anti-predatory strategies, specifically as represented by plastral kinesis (PRITCHARD, 2008), seem to be a main factor of shell differentiation, at least among emydines (ANGIELCZYK et al., 2011). By contrast, phylogenetic inertia seems to play a subsidiary role in turtle shape differentiation, at least in comparison with ecological factors (CLAUDE et al., 2003, 2004; ANGIELCZYK et al., 2011). Although less frequent, intraspecific studies of shape variation also support the importance of habitat effects for turtle morphology. Not only does the shell of aquatic turtles differ from that of terrestrial ones, it is also highly susceptible to the characteristics of water flow. Indeed, RIVERA (2008) showed that freshwater turtles of the genus Pseudemys inhabiting fast-flowing water regimes present a significantly more streamlined shell, while those inhabiting slow-flowing regimes are more domed (Fig. 5). Further supporting an adaptive explanation for the observed
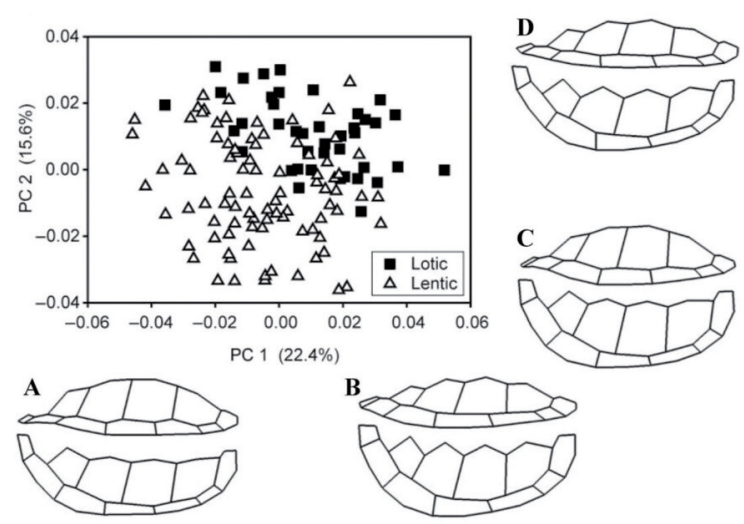

patterns, the shape typical of fast-flowing regimes importantly reduced drag during swimming. Interestingly, a trade-off was also shown to exist between this hydrodynamic efficiency and mechanical strength. Flattened, hydrodynamic shells were more fragile (RIVERA \& STAYTON, 2011), a pattern observed also between aquatic and terrestrial emydids (STAYTON, 2011). The functional relevance of shell shape has also been confirmed in terms of swimming speed, where slider turtles with a relatively wider and shorter plastron attained higher speeds than elongated ones (MYERS et al., 2007).

A wide range of studies have also used GM to decipher the effects of environmental variation on the morphology of amphibians. As is common for this group (WELLS, 2007), multiple studies support the existence of extensive phenotypic plasticity in both head and body shape. Temperature (JorgensEN \& SHEIL, 2008), predation risk (JOHNSON et al., 2008; VAN BUSKIRK, 2009; Hossie et al., 2010), competition (GARRIGA \& LLORENTE, in press), as well as numerous other habitat components (VAN BUSKIRK, 2009) have been shown to produce plastic responses on larval body shape and ontogenetic shape allometry. Furthermore, body shape has been shown to

Figure 5: Three-dimensional shell shape variation observed between male Pseudemys turtles inhabiting fast-flowing and slow-flowing water environments, as visualised through a PCA analysis of the three-dimensional coordinates of the carapace. Individuals of both sexes from lotic habitats are more stream-lined, a shape modification that has also been shown to reduce drag, providing empirical evidence for an adaptive causation of the observed differences (modified with permission from RIVERA, 2008). Deformation grids represent the extreme values observed across the first $(\mathrm{A}, \mathrm{B})$ and second $(\mathrm{C}, \mathrm{D})$ principal component axes. 
be tightly related to swimming performance in anuran larvae (DAYTON et al., 2005; ARENDT, 2010), although the plastic shape modifications observed due to predation do not seem to enhance speed, but may rather be related to tail lure anti-predator display (JOHNSON et al., 2008).

While plasticity studies are dominated by anurans, the investigation of evolutionary shape change as a response to environmental factors is clearly skewed towards salamanders, and particularly those of the genus Plethodon, which have served as an important model system for the evolutionary application of GM tools. Character displacement due to competition has been shown to be a major force of head shape diversification in this genus, which has been associated to both biomechanical (ADAMS \& ROHLF, 2000) and behavioural (ADAMS, 2004) modifications. Undoubtedly, head shape is a trait with strong evolutionary potential in this salamander group, an observation corroborated by the existence of an important heritable component (ADAMS, 2011). However, the detailed studies conducted also reveal that competitive interactions, while repeatable across space when the same pair of species is involved (ADAMS, 2010), are also characterised by important variability (ADAMS et al., 2007; ARIF et al., 2007; MYERS \& ADAMS, 2008), indicating that extrapolation from one pair of species to another can be problematic. While species interactions seem to be of central importance in shaping morphological variation in Plethodon, other factors are also involved. For example, MAERZ et al. (2006) reported significant intraspecific variation associated to trophic polymorphism. Diet also seems to be significantly associated to shape variation of the hyobranchial skeleton of anuran larvae (CANDIOTI, 2006). Other patterns of shape variation in salamanders concern potential adaptation to structural environment, where shape variation among closely related taxa also involves the modification of shape allometries. In a very interesting contrast of evolutionary patterns, JAEKEL \& WAKE (2007) and AdAMS \& NisTRi (2010) respectively described how divergence or convergence of ontogenetic allometries can be modified to produce foot shapes that match the structural environments of Bolitoglossa and Hydromantes salamanders. These two examples nicely illustrate how GM can be used to describe potentially adaptive morphological variation (foot webbing) and associate it to the functional advantages gained by certain shape modifications (capacity for climbing), while also remarking on the importance of ontogenetic trajectories for understanding the evolution of shape - and other - traits (KLINGENBERG, 2010).

Several examples also illustrate the ecomorphological relevance of head/skull shape in lizards. While visibly less integrated than the examples on Plethodon above, the available studies provide evidence to the importance of different ecological factors for shape evolution in various lizard taxa. In an insightful theoretical consideration of convergence in multiple niche dimensions, HARMON et al. (2005) used GM on head shape in Anolis lizards, together with other character sets, to test the hypothesis that if multidimensional convergence really occurs in response to different aspects of the environment, different character systems will show different patterns of convergence among species. In fact, character systems differed and variation in head shape was suggested to be 
due to differences in diet, aggressive or antipredatory behaviour among habitat types (HARMON et al., 2005). The hypothesis that diet may profoundly influence head shape in lizards is also supported by the observation that parallel and convergent evolution occurs between groups specialised in a certain type of diet (STAYTON, 2005, 2006), while the same observation stands for crocodiles (PIERCE et al., 2008). Nevertheless, the strength of such an influence seems to vary across taxonomic levels, since similar studies among gekkotans (DAZA et al., 2009) and the rhynchocephalians (JONES, 2008) indicate that, although head shape is associated to diet, phylogenetic affinity visibly dominates over feeding behaviour as a factor of skull shape differentiation. Considering other factors, both habitat type (Kaliontzopoulou et al., 2010) and insularity (BĂNCILĂ et al., 2010; RAIA et al., 2010) have been shown to influence head shape in lacertid lizards, but these observations should be further tested in other lizard groups.

\section{Systematics, taxonomy and phylogenetic signal}

Due to their increased effectiveness for capturing shape variation, GM methods have been used for species discrimination and for describing morphological variation between closely related, and in many cases cryptic, taxa. For instance, LEACHÉ et al. (2009) used GM on cranial horn shape of the coast horned lizard species complex, combined with a large number of other biologically meaningful traits, to characterise the process of lineage formation in this group. In a similar approach, CHIARI \& Claude (2011) used GM to study carapace size and shape variation in Galápagos tortoises and confirmed the morphological differentia- tion between two genetically distinct lineages, which had been described to differ morphologically using linear methods. GM tools have also been used to analyse intraspecific geographic variation (MANIER, 2004; VIDAL et al., 2005; Clemente-Carvalho et al., 2008; SMith \& COllyer, 2008), investigate the strength of phylogenetic signal in shape data (GENTILLI et al., 2009) and examine the degree of concordance between phylogenetic relatedness and morphological similarity (IVANOVIĆ et al., 2008, 2009). From a purely taxonomical perspective, JAMNICZKY \& RUSSELl (2004) used GM to investigate the "batagurine process", a potential diagnostic character of the turtle family Bataguridae, while VIEIRA et al. (2008) investigated the morphological differentiation between colour morphs of a toad population to examine the taxonomical implications of the observed polymorphism.

While the above studies pose biologically meaningful questions and most use GM in a statistically robust framework to test specific hypotheses, the use of shape characters in phylogeny and systematics has been questioned extensively (ADAMS \& ROSENBERG, 1998; ROHLF, 1998; KLINGENBERG \& GIDASZEWSKI, 2010) and caution is advised when moving in this area of investigation. This predicament lies on both practical and theoretical grounds and is mainly associated to the use of shape variables (either partial warps or their principal components) as cladistic characters (ADAMS et al., 2011). The main difficulty presented is that of transforming continuously varied, multivariate data as shape into discrete character states for parsimony inference (ROHLF, 1998; MONTEIRO, 2000). Additional problems regard the effect of a reference form, which is of central importance to the operations necessary to obtain shape 
variables, and which has been repeatedly shown to deeply influence the results obtained, thus rendering GM shape variables of doubtful usefulness for phylogenetic inference (BoOKSTEIN, 1994; AdAMS \& RosenberG, 1998). This of course does not mean that organismal shape as described by GM methods cannot be analysed in a phylogenetic context, or used to investigate the morphological affinity of closely related species and compare it to their known phylogenetic relationships. Moreover, GM methods often provide a useful tool for obtaining further evidence to support or reject phylogenetic hypotheses (as implemented for example in PIRAS et al., 2010) or to complement the evidence provided by molecular studies (Clemente-CaRvalho et al., 2011) but caution should be taken for correct implementation.

\section{Paleontology}

GM-based methods have been of great utility in paleontology, providing an innovative view of morphological patterns in extinct amphibian and reptile taxa (ELEWA, 2004). Practically all the aforementioned fields have partners in paleontological research, which implement GM as a powerful tool to obtain shape data from samples that frequently suffer in terms of structural quality (BASZIO \& WeBER, 2002; ANGIELCZYK \& SHEETS, 2007). New methods have been developed for the identification of fossils and used to specify the structural position of paleontological findings in snakes (POLLY \& HeAD, 2004), as well as being implemented as an indirect tool of estimating the size of extinct taxa (HEAD et al., 2009). Furthermore, GM methods have aided the investigation of sexual dimorphism in archosaurs, providing evidence for potentially dimorphic structures (BARDEN \& MAIDMENT, 2011) and allowing corroboration of the results through comparison with their extant relatives (i.e. Alligator, Prieto-MARQueZ et al., 2007; BONNAN et al., 2008). Numerous studies have taken advantage of the tool-kit of GM to characterise morphological disparity patterns and investigate their temporal variation and to examine macroevolutionary trends (CANUDO \& Cuenca-Bescós, 2004; StaYton \& Ruta, 2006; Pierce et al., 2009a; Young \& LARVAN, 2010; Young et al. 2010). As for extant groups, shape variation has also been investigated in the light of its functional implications, thus providing a deeper understanding of the paleobiology and paleoecology of archosaur taxa (Bonnan, 2004, 2007; PierCe et al., 2009b; BONNAN et al., 2010). Finally, a very interesting contribution in terms of the originality of the studied shapes is that of RODRIGUES \& Faria DOS Santos (2004), who used GM to investigate the variation of sauropod tracks.

\section{Amphibians and reptiles as models for the deve- lopment of new methods}

The multivariate nature of GM data frequently challenges statistical methods and has stimulated morphometricians to extend existing methods for studying complex shapes. Apart from addressing biological questions, several authors have used amphibians and reptiles as model organisms to develop new methodological approaches that utilise the toolbox of GM and further enhance our capacity of investigating morphological variation. For example, MonTeiro (1999) used GM data on sexual and ontogenetic variation of the skull of tegu lizards to provide a comprehensive review of how multivariate regression tech- 
niques can be implemented to understand the processes and causes underlying shape changes. Along the same lines, MAGWENE (2001) used turtle shells as an example to illustrate how growth fields as characterised by a set of growth vectors could be studied and compared in order to understand the developmental processes involved in ontogenetic shape change. In a conceptually similar approach, COLLYER \& ADAMs (2007) examined character displacement in Plethodon salamanders (ADAMS, 2004) to exemplify the use of shape change vectors for the study of two-state multivariate phenotypic change, an approach later generalized to multistate phenotypic trajectories (ADAMS \& COLLYER, 2009). Also trying to characterise the direction of phenotypic change, STAYTON (2006) proposed a new method for quantifying data disparity patterns and used it to test for convergence in skull shape among herbivorous lizards. In the field of quantitative genetics of shape, MYERS et al. (2006) generalized the univariate approximation of shape heritability based on Procrustes distance (MONTEIRO et al., 2002) for application with unequal sample sizes among families, thus complementing other existing multivariate methods (i.e. KlingenberG， 2003; Klingenberg \& MonTeIro, 2005), and used it to study patterns of plastron shape heritability in slider turtles. A very promising methodology for the field of biomechanics was put forward by PIERCE et al. (2008) and STAYTON (2009), who joined shape theory and finite element models to study the mechanical properties of the crocodilian skull and three-dimensional turtle shell shape correspondingly. Finally, although not directly linked to the study of shape variation, it is worth mentioning the use of GM tools as a means of standardising specimen position for studying colour patterns in salamanders (AsHLOCK et al., 2003; CosTA et al., 2009).

\section{CONCLUDING REMARKS}

The aforementioned studies illustrate the wide range of questions for which GM may be implemented, facilitating the integrated study of shape variation and its causes using amphibians and reptiles as model organisms. Many of these studies have compared traditional morphometric methods to GM and have reached the conclusion that GM techniques are frequently more powerful than linear measurement data for detecting and describing organismal shape variation (VAlenZuela et al., 2004; Bonnan et al., 2008; Kaliontzopoulou et al., 2008; ARENDT, 2010). This is both an advantage and a potential pitfall. On one hand, GM methods are expected to be statistically more powerful in detecting subtle shape variation, since the number of variables analysed is usually much higher than that examined in traditional morphometrics. On the other, caution should be taken in the implementation of such a sensitive tool, to keep with strong biological inference and avoid missing focus of biological hypotheses. As modern technological resources become increasingly available for use in biological sciences, a vast amount of new techniques for obtaining shape data can be explored, including for example computerised tomography (CT) scans and three-dimensional surface scanning. Herpetologists have until now taken full advantage of the technical and statistical tools available for the analysis of shape variation, providing new insights to the evolution of shape and frequently put- 
ting forward new methods for data analysis. Nevertheless, the exploration of GM methods for understanding shape variation in amphibians and reptiles is still an open field, with promising perspectives for future contributions. I hope the above review has provided an informed view of the questions that have been explored and the answers obtained, and point to directions for further inquiry.

\section{Acknowledgement}

I am grateful to the editors of Basic and Applied Herpetology for giving me the opportunity to write this review. D. Adams, M.A. Carretero, G. Rivera and two anonymous reviewers provided useful comments on previous versions of the manuscript. Special thanks to G. Rivera for allowing permission to reproduce figure 5 of his article (as Fig. 5 here). This work was supported by a postdoctoral grant (SFRH/BPD/68493/2010) from Fundação para a Ciência e Tecnologia (FCT, Portugal).

\section{REFERENCES}

ADAMS, D.C. (2004). Character displacement via aggressive interference in Appalachian salamanders. Ecology 85: 2664-2670.

ADAMS, D.C. (2010). Parallel evolution of character displacement driven by competitive selection in terrestrial salamanders. BMC Evolutionary Biology 10: 72.

ADAMS, D.C. (2011). Quantitative genetics and evolution of head shape in Plethodon salamanders. Evolutionary Biology 38: 278-286.

ADAms, D.C. \& Collyer, M.L. (2009). A general framework for the analysis of phe- notypic trajectories in evolutionary studies. Evolution 63: 1143-1154.

Adams, D.C. \& Nistri, A. (2010). Ontogenetic convergence and evolution of foot morphology in European cave salamanders (Family: Plethodontidae). BMC Evolutionary Biology 10: 216.

ADAMS, D.C. \& RohlF, F.J. (2000). Ecological character displacement in Plethodon: Biomechanical differences found from a geometric morphometric study. Proceedings of the National Academy of Sciences USA 97: 4106-4111.

ADAMS, D.C. \& RosenberG, M.S. (1998). Partial warps, phylogeny, and ontogeny: a comment on Fink and Zelditch (1995). Systematic Biology 47: 168-173.

Adams, D.C.; Rohlf, F.J. \& Slice, D.E. (2004). Geometric morphometrics: ten years of progress following the 'revolution'. Italian Journal of Zoology 71: 5-16.

Adams, D.C.; West, M.E. \& Collyer, M.L. (2007). Location-specific sympatric morphological divergence as a possible response to species interactions in West Virginia Plethodon salamander communities. Journal of Animal Ecology 76: 289-295.

Adams, D.C.; Cardini, A.; Monteiro, L.R.; O'Higgins, P. \& Rohlf, F.J. (2011). Morphometrics and phylogenetics: principal components of shape from cranial modules are neither appropriate nor effective cladistic characters. Journal of Human Evolution 60: 240-243.

ANGIELCZYK, K.D. (2007). How to be a miniature turtle: comparisons of ontogeny in the Emydinae using geometric morphometrics. Integrative and Comparative Biology 46 (supplement 1): e3. 
ANGielczyK, K.D. \& SheETs, H.D. (2007). Investigation of simulated tectonic deformation in fossils using geometric morphometrics. Paleobiology 33: 125-148.

AngielczyK, K.D.; Feldman, C.R. \& MilLER, G.R. (2011). Adaptive evolution of plastron shape in emydine turtles. Evolution 65: 377-394.

ARENDT, J. (2010). Morphological correlates of sprint swimming speed in five species of spadefoot toad tadpoles: Comparison of morphometric methods. Journal of Morphology 271: 1044-1052.

ARIF, S.; ADAMS, D.C. \& WiCKNICK, J.A. (2007). Bioclimatic modelling, morphology, and behaviour reveal alternative mechanisms regulating the distributions of two parapatric salamander species. Evolutionary Ecology Research 9: 843-854.

Ashlock, D.; Adams, D.C. \& Doty, D. (2003). Morphometric grayscale texture analysis using foot patterns. Proceedings of the 2003 Congress on Evolutionary Computation: 1575-1582.

BĂNCILĂ, R.; VAn Gelder, I.; RotTeVeel, E.; LOMAN, J. \& ARNTZEN, J.W. (2010). Fluctuating asymmetry is a function of population isolation in island lizards. Journal of Zoology 282: 266-275.

BARDEN, H.E. \& MAIDMENT, S.C.R. (2011). Evidence for sexual dimorphism in the stegosaurian dinosaur Kentrosaurus aethiopicus from the Upper Jurassic of Tanzania. Journal of Vertebrate Paleontology 31: 641-651.

Baszio, S. \& Weber, S. (2002). Potentials and limits of morphometry in the understanding of squamate osteological structures. Senckenbergiana lethaea 82: 13-22.

BirCH, J.M. (1999). Skull allometry in the marine toad, Bufo marinus. Journal of
Morphology 241: 115-126.

Bonnan, M.F. (2004). Morphometric analysis of humerus and femur shape in Morrison sauropods: implications for functional morphology and paleobiology. Paleobiology 30: 444-470.

BonNAN, M.F. (2007). Linear and geometric morphometric analysis of long bone scaling patterns in Jurassic neosauropod dinosaurs: their functional and paleobiological implications. The Anatomical Record 290: 1089-1111.

BONNAN, M.F.; FARLOW, J.O. \& MASTERS, S.L. (2008). Using linear and geometric morphometrics to detect intraspecific variability and sexual dimorphism in femoral shape in Alligator mississippiensis and its implications for sexing fossil archosaurs. Journal of Vertebrate Paleontology 28: 422-431.

BONNAN, M.F.; SANDRIK, J.L.; NiSHIWAKI, T.; Wilhite, D.R.; ElSey, R.M. \& VitTORE, C. (2010). Calcified cartilage shape in archosaur long bones reflects overlying joint shape in stress-bearing elements: Implications for nonavian dinosaur locomotion. The Anatomical Record 293: 2044-2055.

Bookstein, F.L. (1982). Foundations of Morphometrics. Annual Review of Ecology and Systematics 13: 451-470.

Bookstein, F.L. (1986). Size and shape spaces for landmark data in two dimensions. Statistical Science 1: 181-222.

Bookstein, F.L. (1989a). "Size and shape": a comment on semantics. Systematic Zoology 38: 173-180.

BOOKSTEIN, F.L. (1989b). Principal warps: thinplate splines and the decomposition of deformations. IEEE Transactions on Pattern Analysis and Machine Intelligence 11: 567-585.

BooksteIn, F.L. (1991). Morphometric Tools for Landmark Data: Geometry and Biology. 
Cambridge University Press, Cambridge, United Kingdom.

BooKsTEIN, F.L. (1994). Can biometrical shape be a homologous character?, In B.K. Hall (ed.) Homology: The Hierarchical Basis of Comparative Biology. Academic Press, New York, pp. 197-227.

BOOKSTEIN, F.L. (1996). Biometrics, biomathematics and the morphometric synthesis. Bulletin of Mathematical Biology 58: 313-365. BoOKSTEIN, F.L. (1997). Landmark methods for forms without landmarks: localizing group differences in outline shape. Medical Image Analysis 1: 225-243.

Bruner, E. \& Costantini, D. (2007). Head morphological variation in Podarcis muralis and Podarcis sicula: a landmark-based approach. Amphibia-Reptilia 28: 566-573.

Bruner, E.; Costantini, D.; Fanfani, A. \& Dell'Omo, G. (2005). Morphological variation and sexual dimorphism of the cephalic scales in Lacerta bilineata. Acta Zoologica 86: 245-254.

Burke, A.C. (1989). Development of the turtle carapace: implications for the evolution of a novel Bauplan. Journal of Morphology 199: 363-378.

CANDioti, M.F.V. (2006). Ecomorphological guilds in anuran larvae: an application of geometric morphometric methods. Herpetological Journal 16: 149-162.

CANDiOTI, M.F.V. (2008). Larval anatomy of Andean tadpoles of Telmatobius (Anura: Ceratophryidae) from Northwestern Argentina. Zootaxa 1938: 40-60.

Canudo, J.I. \& Cuenca-Bescós, G. (2004). Morphometric approach to Titanosauriformes (Sauropoda, Dinosauria) femora: implications to the paleobiogeographic analysis, In A.M.T. Elewa (ed.) Morphometrics: Applications in
Biology and Paleontology. Springer-Verlag, Berlin, pp. 143-156.

Ceballos, C.P. \& Valenzuela, N. (2011). The role of sex-specific plasticity in shaping sexual dimorphism in a long-lived vertebrate, the snapping turtle Chelydra serpentina. Evolutionary Biology 38: 163-181.

Chiari, Y. \& Claude, J. (2011). Study of the carapace shape and growth in two Galápagos tortoise lineages. Journal of Morphology 272: 379-386.

Claude, J. (2008). Morphometrics with R. Springer, New York.

Claude, J.; Paradis, E.; Tong, H. \& AufFraY, J.-C. (2003). A geometric morphometric assessment of the effects of environment and cladogenesis on the evolution of the turtle shell. Biological Journal of the Linnean Society 79: 485-501.

Claude, J.; Pritchard, P..C.H.; Tong, H.; Paradis, E. \& Aufrray, J.-C. (2004). Ecological correlates and evolutionary divergence in the skull of turtles: a geometric morphometric assessment. Systematic Biology 53: 933-948.

Clemente-Carvalho, R.B.G.; Monteiro, L.R.; Bonato, V.; Rocha, H.S.; Pereira, G.R.; Oliveira, D.F.; Lopes, R.T.; Haddad, C.F.B.; Martins, E.G. \& DOS ReIS, S.F. (2008). Geographic variation in cranial shape in the pumpkin toadlet (Brachycephalus ephippium): a geometric analysis. Journal of Herpetology 42: 176-185.

Clemente-Carvalho, R.B.G.; Alves, A.C.R.; PereZ, S.I.; Haddad, C.F.B. \& dos ReIS, S.F. (2011). Morphological and molecular variation in the pumpkin toadlet, Brachycephalus ephippium (Anura: Brachycephalidae). Journal of Herpetology 45: 94-99. 
Collyer, M.L. \& ADAMS, D.C. (2007). Analysis of two-state multivariate phenotypic change in ecological studies. Ecology 88: 683-692.

Costa, C.; Angelini, C.; Scardi, M.; Menesatti, P. \& Utzeri, C. (2009). Using image analysis on the ventral colour pattern in Salamandrina perspicillata (Amphibia: Salamandridae) to discriminate among populations. Biological Journal of the Linnean Society 96: 35-43.

Costantini, D.; Bruner, E.; Fanfani, A. \& Dell'Omo, G. (2007). Male-biased predation of western green lizards by Eurasian kestrels. Naturwissenschaften 94: 1015-1020.

Costantini, D., Lapresa Alonso, M., Moazen, M. \& Bruner, E. (2010). The relationship between cephalic scales and bones in lizards: a preliminary microtomographic survey on three lacertid species. The Anatomical Record 293: 183-194.

Dayton, G.H.; SAEnZ, D.; BaUm, K.A.; LANGERHANS, R.B. \& DeWITT, T.J. (2005). Body shape, burst speed and escape behavior of larval anurans. Oikos 111: 582-591.

Daza, J.D.; Herrera, A.; Thomas, R. \& Claudio, H.J. (2009). Are you what you eat? A geometric morphometric analysis of gekkotan skull shape. Biological Journal of the Linnean Society 97: 677-707.

Depecker, M.; Berge, C.; Penin, X. \& Renous, S. (2006). Geometric morphometrics of the shoulder girdle in extant turtles (Chelonii). Journal of Anatomy 208: 35-45.

Dryden, I.L. \& MARDiA, K.V. (1998). Statistical Shape Analysis. John Wiley \& Sons, Chichester, United Kingdom.

ElewA, A.M.T. (2004). Introduction, In A.M.T. Elewa (ed.) Morphometrics: Applications in Biology and Paleontology.
Springer-Verlag, Berlin, pp. 1-6.

EMERSON, S.B. \& BRAMble, D.M. (1993). Scaling, allometry, and skull design, In J. Hanken \& B.K. Hall (eds.) The Skull. Volume 3. Functional and Evolutionary Mechanisms. University of Chicago Press, Chicago, pp. 384-421.

Ferson, S.; Rohlf, F.J. \& Koehn, R.K. (1985). Measuring shape variation of two-dimensional outlines. Systematic Zoology 34: 59-68.

GarRiga, N. \& Llorente, G.A. (in press). Chondrocranial ontogeny of Pelodytes punctatus (Anura: Pelodytidae). Response to competition: geometric morphometric and allometric change analysis. Acta Zoologica doi: 10.1111/j.1463-6395.2011.00520.x.

Gentilli, A.; Cardini, A.; Fontaneto, D. \& ZufFI, M.A.L. (2009). The phylogenetic signal in cranial morphology of Vipera aspis: a contribution from geometric morphometrics. Herpetological Journal 19: 69-77.

GOSNER, K.L. (1960). A simplified table for staging anuran embryos and larvae with notes on identification. Herpetologica 16: 183-190.

Gould, S.J. (1966). Allometry and size in ontogeny and phylogeny. Biological Reviews 41: 587-640.

Harmon, L.J.; Kolbe, J.J.; Cheverud, J.M. $\&$ Losos, J.B. (2005). Convergence and the multidimensional niche. Evolution 59: 409-421.

Head, J.J.; Bloch, J.I.; Hastings, A.K.; Bourque, J.R.; Cadena, E.A.; HerRera, F.A.; Polly, P.D. \& JaRAMILLO, C.A. (2009). Giant boid snake from the Palaeocene neotropics reveals hotter past equatorial temperatures. Nature 457: 715-717.

Herrel, A.; McBrayer, L.D. \& Larson, P.M. (2007). Functional basis for sexual 
differences in bite force in the lizard Anolis carolinensis. Biological Journal of the Linnean Society 91: 111-119.

Hossie, T.J.; Ferland-Raymond, B.; Burness, G. \& Murray, D.L. (2010). Morphological and behavioural responses of frog tadpoles to perceived predation risk: A possible role for corticosterone mediation? Ecoscience 17: 100-108.

Huyghe, K.; Herrel, A.; Adriaens, D.; TADIĆ, Z. \& VAN DAMME, R. (2009). It is all in the head: morphological basis for differences in bite force among colour morphs of the Dalmatian wall lizard. Biological Journal of the Linnean Society 96: 13-22.

IVANOvić, A.; Vukov, T.D.; DžUKić, G.; TOMAŠEVIĆ, N. \& KALEZIĆ, M.L. (2007). Ontogeny of skull size and shape changes within a framework of biphasic lifestyle: a case study in six Triturus species (Amphibia, Salamandridae). Zoomorphology 126: 173-183.

IVANOVIĆ, A.; SotiRopoulos, K.; VuKov, T.D.; Eleftherakos, K.; DžUKić, G.; Polymeni, R.M. \& KalEZIĆ, M.L. (2008). Cranial shape variation and molecular phylogenetic structure of crested newts (Triturus cristatus superspecies: Caudata, Salamandridae) in the Balkans. Biological Journal of the Linnean Society 95: 348-360.

IVANOVIĆ, A.; SOTIROPOUlos, K.; DžUkić, G. \& KaLEZIĆ, M.L. (2009). Skull size and shape variation versus molecular phylogeny: a case study of alpine newts (Mesotriton alpestris, Salamandridae) from the Balkan Peninsula. Zoomorphology 128: 157-167.

Ivanović, A.; CVIjanović, M. \& Kalezić, M.L. (2011). Ontogeny of body form and metamorphosis: insights from the crested newts. Journal of Zoology 283: 153-161.
JaEKel, M. \& WAKE, D.B. (2007). Developmental processes underlying the evolution of a derived foot morphology in salamanders. Proceedings of the National Academy of Sciences USA 104: 20437-20442. JamniczKY, H.A. \& Russell, A.P. (2004). A geometric morphometric assessment of the 'batagurine process' of testudinoid turtles. Amphibia-Reptilia 25: 369-379.

Johnson, J.B.; BurT, D.B. \& DeWitt, T.J. (2008). Form, function, and fitness: pathways to survival. Evolution 62: 1243-1251.

JONES, M.E.H. (2008). Skull shape and feeding strategy in Sphenodon and other Rhynchocephalia (Diapsida: Lepidosauria). Journal of Morphology 269: 945-966.

JorGENSEN, M.E. \& SHEIL C.A. (2008). Effects of temperature regime through premetamorphic ontogeny on shape of the chondrocranium in the American toad, Anaxyrus americanus. The Anatomical Record 291: 818-826. Kaliontzopoulou, A.; CarRetero, M.A. \& LLORENTE, G.A. (2007). Multivariate and geometric morphometrics in the analysis of sexual dimorphism variation in Podarcis lizards. Journal of Morphology 268: 152-165.

Kaliontzopoulou, A.; Carretero, M.A. \& Llorente, G.A. (2008). Head shape allometry and proximate causes of head sexual dimorphism in Podarcis lizards: joining linear and geometric morphometrics. Biological Journal of the Linnean Society 93: 111-124.

Kaliontzopoulou, A.; Carretero, M.A. \& LLORENTE, G.A. (2010). Intraspecific ecomorphological variation: linear and geometric morphometrics reveal habitat-related patterns within Podarcis bocagei wall lizards. Journal of Evolutionary Biology 23: 1234-1244.

Kaliontzopoulou, A.; AdAMs, D.C.; VAN DER 
Meijden, A.; Perera, A. \& Carretero, M.A. (in press). Relationships between head morphology, bite performance and ecology in two species of Podarcis wall lizards. Evolutionary Ecology doi: 10.1007/s10682011-9539-y

Kendall, D.G. (1984). Shape-manifolds, Procrustean metrics, and complex projective spaces. Bulletin of the London Mathematical Society 16: 81-121.

Kendall, D.G. (1985). Exact distributions for shapes of random triangles in convex sets. Advances in Applied Probability 17: 308-329.

KlingenberG, C.P. (1996). Multivariate allometry, In L.F. Marcus, M. Corti, A. Loy, G.J.P. Naylor \& D.E. Slice (eds.) Advances in Morphometrics. Series: NATO ASI Series A: Life Sciences, vol. 284. Plenum Press, New York, pp. 23-49.

KLIngenberG, C.P. (2003). Quantitative genetics of geometric shape: heritability and the pitfalls of the univariate approach. Evolution 57: 191-195.

KlingenberG, C.P. (2010). There' s something afoot in the evolution of ontogenies. BMC Evolutionary Biology 10: 221.

KLINGENBERG, C.P. (2011). MorphoJ: an integrated software package for geometric morphometrics. Molecular Ecology Resources 11: 353-357.

KLingenberG, C.P. \& GidAsZEWSKI, N.A. (2010). Testing and quantifying phylogenetic signals and homoplasy in morphometric data. Systematic Biology 59: 245-261.

KLINGENBERG, C.P. \& MONTEIRO, L.R. (2005). Distances and directions in multidimensional shape spaces: implications for morphometric applications. Systematic Biology 54: 678-688.

LARSON, P.M. (2002). Chondrocranial development in larval Rana sylvatica (Anura:
Ranidae): morphometric analysis of cranial allometry and ontogenetic shape change. Journal of Morphology 252: 131-144.

LARSON, P.M. (2004). Chondrocranial morphology and ontogenetic allometry in larval Bufo americanus (Anura, Bufonidae). Zoomorphology 123: 95-106.

LARSON, P.M. (2005). Ontogeny, phylogeny, and morphology in anuran larvae: morphometric analysis of cranial development and evolution in Rana tadpoles (Anura: Ranidae). Journal of Morphology 264: 34-52.

Lawing, A.M. \& Polly, P.D. (2010). Geometric morphometrics: recent applications to the study of evolution and development. Journal of Zoology 280: 1-7.

Leaché, A.D.; KoO, M.S.; SPENCER, C.L.; Papenfuss, T.J.; Fisher, R.N. \& MCGuirE, J.A. (2009). Quantifying ecological, morphological, and genetic variation to delimit species in the coast horned lizard species complex (Phrynosoma). Proceedings of the National Academy of Sciences USA 106: 12418-12423.

LjubisaVljević, K.; UrošEvić, A.; AleKsić, I. \& Ivanović, A. (2010). Sexual dimorphism of skull shape in a lacertid lizard species (Podarcis spp., Dalmatolacerta sp., Dinarolacerta sp.) revealed by geometric morphometrics. Zoology 113: 168-174.

LjubisaVljeVIĆ, K.; Polović, L.; URoŠEvić, A. \& IVANOVIĆ, A. (2011). Patterns of morphological variation in the skull and cephalic scales of the lacertid lizard Algyroides nigropunctatus. Herpetological Journal 21: 65-72.

Lubiana, A. \& Ferreira Júnior, P.D. (2009). Pivotal temperature and sexual dimorphism of Podocnemis expansa hatchlings (Testudines: Podocnemididae) from Bananal Island, Brazil. Zoologia 26: 527-533. 
Maerz, J.C.; Myers, E.M. \& AdAms, D.C. (2006). Trophic polymorphism in a terrestrial salamander. Evolutionary Ecology Research 8: 23-35.

MaGWENE, P.M. (2001). Comparing ontogenetic trajectories using growth process data. Systematic Biology 50: 640-656.

MANIER, M.K. (2004). Geographic variation in the long-nosed snake Rhinocheilus lecontei (Colubridae): beyond the subspecies debate. Biological Journal of the Linnean Society 83: 65-85.

MARCUS, L.F. (1990). Traditional morphometrics, In F.J. Rohlf \& F.L. Bookstein (eds.) Proceedings of the Michigan Morphometrics Workshop. Series: Special Publications, vol. 2. University of Michigan Museum of Zoology, Ann Arbor, Michigan, USA, pp. 77-122.

Mitteroecker, P. \& GunZ, P. (2009). Advances in geometric morphometrics. Evolutionary Biology 36: 235-247.

Monteiro, L.R. (1999). Multivariate regression models and geometric morphometrics: the search for causal factors in the analysis of shape. Systematic Biology 48: 192-199.

MonTeiro, L.R. (2000). Why morphometrics is special: the problem with using partial warps as characters for phylogenetic inference. Systematic Biology 49: 796-800.

Monteiro, L.R. \& ABe, A.S. (1997). Allometry and morphological integration in the skull of Tupinambis merianae (Lacertilia: Teiidae). Amphibia-Reptilia 18: 397-405.

Monteiro, L.R.; Cavalcanti, M.J. \& SOMmer III, H.J.S. (1997). Comparative ontogenetic shape changes in the skull of Caiman species (Crocodylia, Alligatoridae). Journal of Morphology 231: 53-62.

MONTEIRO, L.R.; DINIZ-FILHO, J.A.F.; DOS REIS, S.F. \& ARAúJO, E.D. (2002). Geometric esti- mates of heritability in biological shape. Evolution 56: 563-572.

Myers, E.M. \& ADAMS, D.C. (2008). Morphology is decoupled from interspecific competition in Plethodon salamanders in the Shenandoah Mountains, USA. Herpetologica 64: 281-289.

Myers, E.M.; Janzen, F.J.; AdAMs, D.C. \& TUCKER, J.K. (2006). Quantitative genetics of plastron shape in slider turtles (Trachemys scripta). Evolution 60: 563-572.

Myers, E.M.; TuCKer, J.K. \& Chandler, C.H. (2007). Experimental analysis of body size and shape during critical lifehistory events of hatchling slider turtles, Trachemys scripta elegans. Functional Ecology 21: 1106-1114.

NishiZAWA, H.; AsAHARA, M.; KAMEZAKI, N. \& ARAI, N. (2010). Differences in the skull morphology between juvenile and adult green turtles: implications for the ontogenetic diet shift. Current Herpetology 29: 97-101.

O'Higgins, P. \& Jones, N. (2006). Tools for Statistical Shape Analysis. Hull York Medical School, York-Hull, United Kingdom. Available at http://sites.google.com/site/hymsfme/resources. Retrieved on 08/20/2011.

PIERCE, S.E.; ANGIELCZYK, K.D. \& RAYFIELD, E.J. (2008). Patterns of morphospace occupation and mechanical performance in extant crocodilian skulls: a combined geometric morphometric and finite element modeling approach. Journal of Morphology 269: 840-864.

Pierce, S.E.; ANGIElCZyK, K.D. \& Rayfield, E.J. (2009a). Morphospace occupation in thalattosuchian crocodylomorphs: skull shape variation, species delineation and temporal patterns. Palaeontology 52: 1057-1097. 
Pierce, S.E.; AngielczyK, K.D. \& Rayfield, E.J. (2009b). Shape and mechanics in thalattosuchian (Crocodylomorpha) skulls: implications for feeding behaviour and niche partitioning. Journal of Anatomy 215: 555-576.

Piras, P.; Colangelo, P.; Adams, D.C.; Buscalioni, A.; Cubo, J.; Kotsakis, T.; Meloro, C. \& Raia, P. (2010). The Gavialis-Tomistoma debate: the contribution of skull ontogenetic allometry and growth trajectories to the study of crocodylian relationships. Evolution \& Development 12: 568-579.

Polly, P.D. \& HEAD, J.J. (2004). Maximumlikelihood identification of fossils: taxonomic identification of Quaternary marmots (Rodentia, Mammalia) and identification of vertebral position in the pipesnake Cylindrophis (Serpentes, Reptilia), In A.M.T. Elewa (ed.) Morphometrics: Applications in Biology and Paleontology. Springer-Verlag, Berlin, pp. 197-222.

Prieto-Marquez, A.; Gignac, P.M. \& Joshi, S. (2007). Neontological evaluation of pelvic skeletal attributes purported to reflect sex in extinct non-avian archosaurs. Journal of Vertebrate Paleontology 27: 603-609.

Pritchard, P.C.H. (2008). Evolution and structure of the turtle shell, In J. Wyneken, M.H. Godfrey \& V. Bels (eds.) Biology of Turtles. CRC Press, Boca Raton, Florida, USA, pp. 45-83.

R Development Core Team (2010). $R$ : $A$ Language and Environment for Statistical Computing. R Foundation for Statistical Computing, Vienna, Austria. Available at http://www.r-project.org/. Retrieved on 08/20/2011.

Raia, P.; Guarino, F.M.; Turano, M.; POlese, G.; Rippa, D.; Carotenuto, F.; Monti,
D.M.; Cardi, M. \& Fulgione, D. (2010). The blue lizard spandrel and the island syndrome. BMC Evolutionary Biology 10: 289.

RiverA, G. (2008). Ecomorphological variation in shell shape of the freshwater turtle Pseudemys concinna inhabiting different aquatic flow regimes. Integrative and Comparative Biology 48: 769-787.

Rivera, G. \& Claude, J. (2008). Environmental media and shape asymmetry: a case study on turtle shells. Biological Journal of the Linnean Society 94: 483-489.

Rivera, G. \& STAYTON, C.T. (2011). Finite element modeling of shell shape in the freshwater turtle Pseudemys concinna reveals a tradeoff between mechanical strength and hydrodynamic efficiency. Journal of Morphology 272: 1192-1203.

Rodrigues, L.A. \& Faria dos Santos, V. (2004). Sauropod Tracks - a geometric morphometric study, In A.M.T. Elewa (ed.) Morphometrics: Applications in Biology and Paleontology. Springer-Verlag, Berlin, pp. 129-142.

RoHLF, F.J. (1986). Relationships among eigenshape analysis, Fourier analysis, and analysis of coordinates. Mathematical Geology 18: 845-854.

RoHLF, FJ. (1990). Fitting curves to outlines, In FJ. Rohlf \& F.L. Bookstein (eds.) Proceedings of the Michigan Morphometrics Workshop. Series: Special Publications, Vol. 2. University of Michigan Museum of Zoology, Ann Arbor, Michigan, USA, pp. 167-177.

RoHLF, F.J. (1998). On applications of geometric morphometrics to studies of ontogeny and phylogeny. Systematic Biology 47: 147-158.

RoHLF, FJ. (1999). Shape statistics: Procrustes superimpositions and tangent spaces. 
Journal of Classification 16: 197-223.

RoHlF, F.J. (2000a). On the use of shape spaces to compare morphometric methods. Hystrix 11: 9-25.

RoHlF, F.J. (2000b). Statistical power comparisons among alternative morphometric methods. American Journal of Physical Anthropology 111: 463-478.

RoHLF, F.J. (2003). Bias and errors in estimates of mean shape in geometric morphometrics. Journal of Human Evolution 44: 665-683.

RoHLF, F.J. (2011). Morphometrics at SUNY Stony Brook. Department of Ecology and Evolution, State University of New York, Stony Brook, New York, USA. Available at http://life.bio.sunysb.edu/morph/. Retrieved on 11/16/2011.

RoHLF, F.J. \& ARCHIE, J.W. (1984). A comparison of Fourier methods for the description of wing shape in mosquitoes (Diptera: Culicidae). Systematic Zoology 33: 302-317.

Rohlf, F.J. \& BoOKstein, F.L. (1987). A comment on shearing as a method for "size correction”. Systematic Zoology 36: 356-367.

RoHlF, F.J. \& MARCUS, L.F. (1993). A revolution morphometrics. Trends in Ecology and Evolution 8: 129-132.

Rohlf, F.J. \& SliCE, D. (1990). Extensions of the Procrustes method for the optimal superimposition of landmarks. Systematic Zoology 39: 40-59.

SHEETS, H.D. (2000). Integrated Morphometrics Package (IMP). Canisius College, Buffalo, New York, USA. Available at http://www2.canisius.edu/ - sheets/. Retrieved on 08/20/2011.

Siegel, A.F. \& Benson, R.H. (1982). A robust comparison of biological shapes. Biometrics 38: 341-350.

SLICE, D.E. (2001). Landmark coordinates aligned by Procrustes analysis do not lie in Kendall's shape space. Systematic Biology 50: 141-149.

SLICE, D.E. (2005). Modern morphometrics, In D.E. Slice (ed.) Modern Morphometrics in Physical Anthropology. Series: Developments in Primatology: Progress and Prospects (R.H. Tuttle, ed.). Kluwer Academics / Plenum Publishers, New York, pp. 1-46.

Slice, D.E.; BoOKSTEIN, F.L.; MARCus, L.F. \& RoHLF, F.J. (1996). Appendix I. A glossary for geometric morphometrics, In L.F. Marcus, M. Corti, A. Loy, G.J.P. Naylor \& D.E. Slice (eds.) Advances in Morphometrics. Series: NATO ASI Series A: Life Sciences, vol. 284. Plenum Press, New York, pp. 531-551.

Smith, M.T. \& Collyer, M.L. (2008). Regional variation and sexual dimorphism in head form of the prairie rattlesnake (Crotalus viridis viridis): comparisons using new analytical techniques and collection methods, In W.K. Hayes, K.R. Beaman, M.D. Cardwell \& S.P. Bush (eds.) The Biology of Rattlesnakes. Loma Linda University Press, Loma Linda, California, USA, pp. 79-90.

SOKAL, R.R. \& ROHLF, F.J. (1995). Biometry: The Principles and Practice of Statistics in Biological Research, 3rd ed. W.H. Freeman, New York.

StAYTON, C.T. (2005). Morphological evolution of the lizard skull: A geometric morphometrics survey. Journal of Morphology 263: 47-59. STAYTON, C.T. (2006). Testing hypotheses of convergence with multivariate data: morphological and functional convergence among herbivorous lizards. Evolution 60: 824-841.

STAYTON, C.T. (2009). Application of thinplate spline transformations to finite element models, or, how to turn a bog turtle into a spotted turtle to analyze both. 
Evolution 63: 1348-1355.

STAYTON, C.T. (2011). Biomechanics on the half shell: functional performance influences patterns of morphological variation in the emydid turtle carapace. Zoology 114: 213-223.

StAYTON, C.T. \& RUTA, M. (2006). Geometric morphometrics of the skull roof of stereospondyls (Amphibia: Temnospondyli). Palaeontology 49: 307-337.

Thompson, D.W. (1917). On Growth and Form. Cambridge University Press, Cambridge, United Kingdom.

Valenzuela, N.; Adams, D.C.; Bowden, R.M. \& GAUGER, A.C. (2004). Geometric morphometric sex estimation for hatchling turtles: a powerful alternative for detecting subtle sexual shape dimorphism. Copeia 2004: 735-742.

VAN BUSKIRK, J. (2009). Natural variation in morphology of larval amphibians: Phenotypic plasticity in nature? Ecological Monographs 79: 681-705.

Vidal, M.A.; OrTiZ, J.C.; Ramírez, C.C. \& LAMBOROT, M. (2005). Intraspecific variation in morphology and sexual dimorphism in Liolaemus tenuis (Tropiduridae). Amphibia-Reptilia 26: 343-351.

VidAl, M.A.; Veloso, A. \& Méndez, M.A. (2006). Insular morphological divergence in the lizard Liolaemus pictus (Liolaemidae). Amphibia-Reptilia 27: 103-111.

Vieira, K.S.; ARZABe, C.; HernándeZ, M.I.M. \& VIEIRA, W.L.S. (2008). An examination of morphometric variations in a neotropical toad population (Proceratophrys cristiceps, Amphibia, Anura, Cycloramphidae). PloS ONE 3: e3934.

Wells, K.D. (2007). The Ecology and Behavior of Amphibians. The University of Chicago Press, Chicago.

Witzmann, F; Scholz, H. \& RutA, M. (2009). Morphospace occupation of temnospondyl growth series: a geometric morphometric approach. Alcheringa 33: 237-255.

Young, M.T. \& LARVAN, M.D. (2010). Macroevolutionary trends in the skull of sauropodomorph dinosaurs - the largest terrestrial animals to have ever lived, In A.M.T. Elewa (ed.) Morphometrics for Nonmorpometricians. Series: Lecture Notes in Earth Sciences, vol. 124. Springer-Verlag, Berlin, pp. 259-269.

YounG, M.T.; BRUSATTE, S.L.; RUTA, M. \& DE ANDRADE, M.B. (2010). The evolution of Metriorhynchoidea (mesoeucrocodylia, thalattosuchia): an integrated approach using geometric morphometrics, analysis of disparity, and biomechanics. Zoological Journal of the Linnean Society 158: 801-859.

Zelditch, M.L.; Swiderski, D.L.; Sheets, H.D. \& FInK, W.L. (2004). Geometric Morphometrics for Biologists: A Primer. Elsevier Academic Press, San Diego, California, USA.

Zuffi, M.A.L.; SACChI, R.; Pupin, F. \& Cencetti, T. (2011). Sexual size and shape dimorphism in the Moorish gecko (Tarentola mauritanica, Gekkota, Phyllodactylidae). North-Western Journal of Zoology 7: 189-197. 


\section{APPENDIX 1: SOFTWARE RESOURCES}

Several software packages have been developed for the application of GM methods, including data acquisition (digitising landmarks), obtaining shape variables and performing exploratory analyses and hypothesis-testing. A detailed account of all available software, as well as numerous other useful resources, can be found in the SUNY Morphometrics webpage developed and maintained by F.J. Rohlf (http://life.bio.sunysb.edu/morph). All programs are freely available for download. Here I briefly provide an account of the main software packages more frequently used in recent publications. Apart from the software mentioned below, all GM procedures can also be carried out in $\mathrm{R}$ language ( $\mathrm{R}$ DEVELOPMENT CORE TEAM, 2010), with an extremely high flexibility for data visualisation and analysis. The book "Morphometrics with R" (CLAUDE, 2008) is the essential guide for this purpose.

The tps series (ROHLF, 2011): Developed since the early days of GM, this is a series of software packages that aid the user in treating different aspects related to the acquisition and analysis of GM data. Rather than an integrated package, this is a series of programs, each thought for carrying out specific operations or answering relevant biological questions. In this sense, the tps programs are organised conceptually, depending on the operations or statistical analyses of interest. Different programs provide utility operations (tpsUtil) and landmark acquisition (tpsDig), superimposition methods (tpsSuper), modelling shape variation through the thin-plate spline and related methods (tpsRelW; tpsSplin) and a wide array of more specific exploratory and statistical procedures such as the visualization of thin-plate splines on trees (tpsTree), regression of shape onto independent variables and regression-related hypothesis testing (tpsRegr) and two-block partial least squares analysis (tpsPLS). Although some users might find the separation in different programs troublesome, this is a very question-driven software series, specifically designed for answering shape-related questions and accompanied by extremely thorough help pages that provide the user with both a conceptual and mathematical understanding of the operations involved. Both 2D and 3D analyses are supported. Designed for use in Windows, but will run without problems in Linux using Wine.

MorphoJ (KLingenberG, 2011): A userfriendly integrated software package that provides a platform for the most important types of analyses usually carried out with GM data. These include 2D and 3D Procrustes superimposition with and without object symmetry, utility operations, generation of covariance matrices, matrix correlation, principal components analysis, two-block partial least squares, canonical variate and linear discriminant analyses, regression analysis, mapping shapes onto a phylogeny and calculation of phylogenetic independent contrasts and analyses related to the quantitative genetics of shape. Written in Java, it is a practically platform-independent program that will run on all Windows, Macintosh OS X and Linux.

IMP (SHEETS, 2000): This is a set of six basic and several other auxiliary programs for analysing GM data. It will perform all the usual GM operations, including the generation of shape coordinates, principal components analysis, canonical variate analysis, 
shape regression and pair-wise multivariate shape comparisons. Both $2 \mathrm{D}$ and $3 \mathrm{D}$ analyses are supported. It is based on MATLAB, but will work without this software being installed on the computer. It is a Windowsbased program, but will apparently run well on MAC and Linux through emulators.

Morphologika (O' Higgins \& Jones, 2006): A set of integrated tools for examining size and shape variation among objects described by configurations of both 2D and 3D landmark coordinates. It enables generalised Procrustes fitting of configurations, tangent space projection, PCA of shape or size and shape, multivariate regression of shape on an independent variable, visualization of size and shape variations by warping of the mean or computation of transformation grids. As for the tps-series, shape variables can be exported and more mainstream multivariate analyses are to be carried out in external statistical software. Although still frequently used, morphologika is no longer maintained and has rather been replaced by the EVAN toolbox (http://www.evansociety.org), which is more oriented to $3 \mathrm{D}$ shape analysis. 